\title{
DERECHO PRESUPUESTARIO ESPAN̄OL: TEXTO REFUNDIDO DE LA LEY GENERAL PRESUPUESTARIA (RDL 1091/88, DE 23 DE SEPTIEMBRE) \\ LEY REGULADORA DE LAS BASES DEL REGIMEN LOCAL 7/85 DE 2 DE ABRIL Y CONCORDANTES LEY 39/1988, DE 28 DE DICIEMBRE,
REGULADORA DE LAS HACIENDAS LOCALES
}

POR

José Luis Fayos Apesteguía

\begin{abstract}
sumario: I. Introducción.-II. Concepto de los Presupuestos Generales del Estado.-III. Principios presupuestarios.-IV. Estructura de los Presupuestos Generales del Estado.-V. Contenido de los Presupuestos Generales del Estado.-VI. El ciclo PResupuestario: 1. Elaboración. 2. Aprobación. 3. Créditos extraordinarios y suplementos de crédito. 4. Ejecución. 5. Liquidación y cierre del ejercicio.-VII. ConCEPto $y$ efectos de los Presupuestos de las entidades locales. - VIII. Los principios presupuestarios en la esfera local.-IX. Referencia al proyecto de la Ley Reguladora de las Haciendas locales. - X. Estructura de los Presupuestos locales. -XI. Elaboración Y aprobación de los Presupuestos locales.-XII. Ejecución de los Presupuestos locales.-XIII. Dinamica del gasto: gestión y contabilidad de la Administración loCal.-XIV. La fiscalizacion del gasto.-XV. Tecnicas de fiscalización.
\end{abstract}

\section{INTRODUCCION}

Se nos ha planteado la realización de un trabajo que verse sobre la novísima Ley General Presupuestaria, cuyo Texto Refundido se ha aprobado por Real Decreto Legislativo 1091/88, de 23 de septiembre.

Nuestro estudio no se va a extender a todo el articulado, ni a todos los temas que regula la citada norma; sin embargo, va a exceder al contenido de la misma puesto que la parte escogida, Presupuestos, la analizaremos desde otros textos legales en los que sin duda se introducirán especialidades, que no modificaciones, toda vez que los mismos tienen por destinataria a la Administración local; las normas que hemos apuntado son, entre otras, la Ley 7/85, de 2 de abril, Reguladora de las Bases del Régimen Local, y el Real Decreto Legislativo 781/86, de 18 de abril, que aprueba el Texto Refundido de las disposiciones legales vigentes en materia de régimen local, además de otras normas de rango inferior. 
Una vez definido el objeto de nuestro estudio, esto es, el Presupuesto, que será visto tanto desde el prisma de la Administración central como de la local, creemos conveniente hacer alusión al sistema trazado para realizar nuestro trabajo. Así, nos ocuparemos del concepto, principios, estructura y contenido del Presupuesto, para entrar, más tarde, en lo que denominaremos ciclo presupuestario y que abarca su elaboración, aprobación, modificaciones, ejecución y liquidación. Igualmente, y por último, trataremos el control del gasto público.

Antes de entrar en materia, queremos reflexionar como introducción en la actividad económica. El Estado es un sujeto más de ésta y participa de ella bien indirectamente, para la producción de bienes económicos en igualdad con los restantes sujetos (particulares y empresas); bien directamente para la satisfacción de determinadas necesidades públicas a través de los ingresos y gastos públicos (actividad financiera). Esta actividad financiera del Estado se diferencia de la economía privada en dos notas fundamentales:

1. - El sujeto de la actividad financiera es el Estado en el ejercicio de la autoridad política (poder de coacción).

2.․ Se fiscaliza por los ciudadanos a través del control parlamentario.

De la naturaleza jurídica de esta actividad estatal se ha ocupado la doctrina y las tendencias que han surgido pueden clasificarse en: económicas y político-sociológicas. Entre los defensores de la primera destacan los cameralistas, el liberalismo y la teoría marginalista y la consideran como una parte de la actividad económica; Seligman y Fasiani, representantes de la tendencia político-sociológica, mantienen que la actividad financiera es fruto de una decisión política de la autoridad de gobierno.

La actividad financiera se materializa en la aplicación de los ingresos y gastos públicos para el logro de determinadas finalidades, el centro de estas elecciones lo constituye el Presupuesto, que refleja el plan económico del grupo político (Fuentes Quintana). Aparece así, pues, el Presupuesto como una institución a través de la cual la sociedad elige cómo administrar los recursos escasos de una forma óptima y racional.

En España podemos decir que el primer Presupuesto surgió en 1835. Las normas que han venido regulando los principios por los que se regían, estaban contenidas en un primer momento en la Ley de 1911 de Administración y Contabilidad, vigente hasta la publicación de la Ley $11 / 77$, de 4 de enero, Ley General Presupuestaria, que sufría modificaciones anuales con la aprobación de la Ley de Presupuestos del Estado de cada ejercicio, en vigor, con respecto al 
contenido del artículo 134 de la Constitución española, hasta la publicación del Texto Refundido que mencionábamos al principio.

\section{CONCEPTO DE LOS PRESUPUESTOS GENERALES DEL ESTADO}

Para dar un concepto, de este principal documento del que pueden examinarse todos los aspectos económicos de la posición de un país, podemos acudir a la doctrina y a la legislación. Así, algunos autores como Neumark ponen el énfasis en la previsión y lo definen como:

«El Presupuesto es un resumen sistemático, confeccionado en períodos regulares, de las previsiones, en principio obligatorias, de los gastos proyectados, y de las estimaciones de los ingresos previstos para cubrir dichos gastos".

Otros autores, sin embargo, se fijan en el aspecto político (Duverger y Sainz de Bujanda), y configuran el presupuesto como un compromiso legal para el ejecutivo, constituyendo el límite máximo de gasto autorizado por el Parlamento.

Para Naharro Mora, el Presupuesto es «la expresión contable del Plan económico de la Hacienda para un período determinado»; por último, dictaremos la definición de Rodríguez Bereijo, para quien es «un acto normativo, que bajo la forma de Ley da eficacia y valor jurídico a los ingresos y gastos previstos".

En base a estas definiciones, podemos determinar que el Presupuesto surge por la necesidad de ordenar los ingresos y gastos del grupo político y la de concretar en un documento las atribuciones que el poder legisiativo concede al ejecutivo; asimismo podemos dar unas notas comunes:

- Comprenden ingresos y gastos públicos.

- Se trata de una previsión normativa y contable.

- Los gastos deben corresponder con los ingresos.

- Tienen una vigencia determinada (ejercicio presupuestario).

- Su contenido es vinculante.

Pero además de estos conceptos doctrinales, podemos encontrar otros en las normas que se ocupan del Presupuesto, así, la Ley General Presupuestaria de 1977, en su artículo 48 establece: 
«Los Presupuestos Generales del Estado constituyen la expresión cifrada, conjunta y sistemática de las obligaciones que como máximo, pueden reconocer el Estado y sus organismos autónomos y de los derechos que se prevean liquidar durante el correspondiente ejercicio».

También la Constitución española de 1978, en su artículo 134.2 nos define el Presupuesto, definición que recoge las notas que antes mencionábamos, y dice: «Los Presupuestos Generales del Estado tendrán carácter anual, incluirán la totalidad de los gastos e ingresos del sector público estatal y en ellos se consignarán el importe de los beneficios fiscales que afecten a los tributos del Estado».

Por último, la nueva Ley General Presupuestaria también nos define el Presupuesto, concepto que recoge, al igual que la Ley que viene a sustituir, en el artículo 48 , y dice:

«1. Los Presupuestos Generales del Estado constituyen la expresión cifrada, conjunta y sistemática de:

a) Lás obligaciones que, como máximo, pueden reconocer el Estado y sus organismos autónomos y los derechos que se prevean liquidar durante el correspondiente ejercicio.

b) La totalidad de las obligaciones que haya de atender la Seguridad Social, tanto en su régimen general como en sus regímenes especiales, y los recursos previstos para el ejercicio correspondiente.

c) Las estimaciones de gastos e ingresos a realizar por las sociedades estatales.

d) La totalidad de los gastos e ingresos del resto de entes del sector público estatal a que se refiere el artículo 6.5 de la propia Ley General Presupuestaria.

2. En los Presupuestos Generales del Estado se consignarán de forma ordenada y sistemática, el importe de los beneficios fiscales que afecten a los tributos del Estado».

Si comparamos los tres preceptos citados, nos encontramos con una casi total identificación. Así podemos decir que el concepto contenido en la nueva y vigente Ley General Presupuestaria recoge el de la Ley de 1977, si bien lo amplía al especificar los presupuestos de la Seguridad Social, sociedades estatales y otros entes del sector público. También se recoge en este nuevo texto la referencia a los beneficios fiscales que afecten a los tributos del Estado, mención aparecida en la Constitución; así, pues, la Ley de 1988 refunde los conceptos de la anterior Ley Presupuestaria y de la Norma Suprema aunque con un carácter más extenso como acabamos de ver. 


\section{PRINCIPIOS PRESUPUESTARIOS}

Una vez realizada, más o menos, la delimitación conceptual del Presupuesto, vamos a ocuparnos de los principios, principios presupuestarios a los que debe de ajustarse el gasto público y que ya son clásicos en el mundo de la Hacienda pública. Sin embargo se encuentran actualmente en crisis debido al constante incremento del gasto público.

Podemos distinguir los siguientes principios:

- Políticos.

- Contables.

- Económicos.

Dentro de los principios políticos nos encontramos con:

\section{Competencia}

Hace referencia al órgano encargado de la aprobación del Presupuesto y según el artículo 134 de la Constitución española corresponde al poder legislativo.

\section{Universalidad}

Se indica con este principio que deben de figurar en el Presupuesto todos los gastos e ingresos. No deben confundirse con el de unidad, pues este que tratamos excluye la práctica de compensaciones. Se denomina también «regla del producto bruto».

Este principio permite un control efectivo del Parlamento sobre los gastos e ingresos. Se ha dicho que entorpece el funcionamiento de los servicios públicos, esta rigidez se atenúa acudiendo a las «cajas negras» o "mercados de conversión», operación amparada por la Ley en su artículo 71.b según el cual los ingresos derivados de enajenaciones de bienes del Estado, o de sus organismos autónomos, pueden generar créditos en los estados de gastos de los Presupuestos, según reglamentariamente se establezca.

\section{Unidad}

Implica la existencia de un solo Presupuesto y la aprobación simultánea de un solo acto de decisión de todos los ingresos y gastos del Estado.

Este principio que podría conducir a la existencia de un Presupuesto para cada ente con personalidad jurídica y así se determinaba en el 
artículo 51.2 de la Ley de 1977, al preveer que debía unirse al Presupuesto General del Estado, el Presupuesto resumen de los organismos autónomos de carácter comercial, industrial, financiero o análogos y el de la Seguridad Social, debe considerarse modificado en el sentido de un único Presupuesto tras la publicación de la Constitución española (art. 134.2), que establece que los Presupuestos incluirán la totalidad de los gastos e ingresos del sector público estatal y la nueva LGP en su artículo 50.

\section{Anualidad}

Principio que tiene un doble aspecto, uno referido a la aprobación y otro a la ejecución.

En el primero, la anualidad significa que la Ley de Presupuestos tiene limitada su vigencia a un año, y en el segundo que las operaciones de ejecución del Presupuesto deben realizarse dentro del período anual, imputándose a sus cuentas únicamente las que cumplan esta condición.

Esta determinación temporal viene recogida en el artículo 34.2 de la CE y artículo 49 de la LGP, que por otra parte identifica la anualidad con el año natural.

\section{Publicidad}

En cuanto a los principios contables podemos señalar:

1.. Unidad de caja.

2.․ Ejercicio cerrado, puesto que el Presupuesto se ejecuta en un período o plazo determinado.

3. - No afectación. Principio que postula que todos los ingresos públicos se destinen de manera indistinta y global a la cobertura de los gastos, por lo que no se reconoce la prioridad de ninguno de éstos respecto a una determinada fuente de financiación.

Esta determinación se encuentra expresamente recogida en el artículo 23 de la LGP de 1988, que permite como excepción la afectación a fines determinados cuando así lo establezca una Ley.

$Y$ por último, vamos a enumerar alguno de los principios económicos, destacando:

1.․ Limitación del gasto público.

2.․ Equilibrio presupuestario.

3.․ Neutralidad impositiva.

4. - Deuda pública autoliquidable. 


\section{ESTRUCTURA DE LOS PRESUPUESTOS GENERALES DEL ESTADO}

El artículo 134.2 de la CE establece que los Presupuestos Generales del Estado incluirán la totalidad de los gastos e ingresos del sector público estatal.

Por su parte, el artículo 52 del TRLGP establece:

«La estructura de los Presupuestos Generales del Estado se determinará por el Ministerio de Economía y Hacienda, teniendo en cuenta la organización del Estado, de sus organismos autónomos y demás entidades integrantes del sector público estatal, la naturaleza económica de los ingresos y de los gastos, y las finalidades u objetivos que con estos últimos se propongan conseguir: A los Jefes de los departamentos ministeriales corresponderá desarrollar la estructura presupuestaria de las entidades públicas y organismos autónomos de ellos dependientes, con arreglo a sus características, pero adaptándose a la que se establezca para el sector público.»

De lo señalado en estos artículos se desprende que primero hay que distinguir entre estado de ingresos y estado de gastos.

A continuación el artículo 53 del mismo texto legal preceptúa una serie de reglas refiriéndose en su parte primera al estado de gastos y en su parte segunda al estado de ingresos.

Así respecto del estado de gastos de los Presupuestos Generales del Estado se aplicarán las clasificaciones orgánica, funcional desagregada en programas y económica, es decir, el presupuesto de gastos tiene una clasificación múltiple.

La clasificación orgánica agrupará los créditos para gastos por cada servicio (art. 53.a).

Estructura por centros gestores:

Distingue las unidades que participan en los programas y a tal efecto se les dota de créditos presupuestarios.

Los centros gestores se clasifican en:

a) Secciones: correspondientes a los Altos Organos Constitucionales del Estado (Casa del Rey, Cortes Generales, Tribunal de Cuentas, Tribunal Constitucional, Consejo de Estado y Consejo General del Poder Judicial); departamentos ministeriales y las que se podrían denominar secciones instrumentales (Deuda pública, clases pasivas, gastos de diversos ministerios, entes territoriales y Junta de Compensación Interterritorial). 
b) Servicios: De cada sección, éstas se articulan por servicios, que comprende no sólo los centros directivos del Departamento Ministerial, sino también los organismos autónomos dependientes.

La clasificación funcional agrupará los créditos según la naturaleza de las actividades a realizar (art. 53.b).

Los órganos constitucionales, los departamentos ministeriales, los demás órganos del Estado con dotaciones diferenciadas en los Presupuestos Generales del Estado y los organismos autónomos establecerán, de acuerdo con el Ministerio de Economía y Hacienda, un sistema de objetivos que sirva de marco a su gestión presupuestaria $y$, de conformidad con ellos, se clasificarán los créditos por programas (art. 53.c):

La distribución de los recursos financieros se efectúa en función de los objetivos que se pretenden conseguir, agrupados en programas.

Los programas se agregan en subfunciones, funciones y grupos de funciones, de acuerdo con la estructura funcional y de programas.

a) Grupos de funciones: constituyen las grandes esferas de actuación del Estado, encaminadas a la realización de las metas institucionales.

b) Funciones: agrupan los programas, según las finalidades que éstos cumplen.

c) Subfunciones: se configuran como un nivel intermedio de agregación de programas, en base a la naturaleza de las actividades que realizan.

d) Programas: son un conjunto de actividades encaminados a la consecución de objetivos análogos y coherentes.

Los programas pueden dividirse en subprogramas cuando lo aconsejen la naturaleza de los objetivos.

Por último, por lo que se refiere a la clasificación económica el artículo 53.d establece que se presentarán con separación los gastos corrientes y los gastos de capital, así como los criterios por los que se regirán:

1.o En los créditos para gastos corrientes se distinguirán los de funcionamiento de los servicios, los gastos financieros y las transferencias corrientes.

2. En los créditos para gastos de capital se distinguirán los de inversiones reales, las transferencias de capital y las variaciones de activos y pasivos financieros. 
Junto a esta estructura denominada operativa, está la clasificación por categorías económicas de los gastos agrupados en:

a) Capítulos: comprensivos de los grandes apartados del gasto. logos.

b) Artículos: desglose de los capítulos, agrupando gastos análeza.

c) Conceptos: clasificación de los gastos conforme a su natura-

d) Subconceptos: especificación de los gastos incluidos en un concepto.

Cuadro. Clasificación económica del Presupuesto de Gastos

A) Operaciones corrientes

Capítulo 1. Renumeraciones de personal.

Capítulo 2. Compra de bienes corrientes y servicios.

Capítulo 3. Intereses.

Capítulo 4. Transferencias corrientes.

B) Operaciones de capital

Capítulo 6. Inversiones reales.

Capítulo 7. Transferencias de capital.

Capítulo 8. Variación de activos financieros.

Capítulo 9. Variación de pasivos financieros.

En cuanto al estado de ingresos el artículo 53 establece en su parte segunda que «el estado de ingresos del Presupuesto del Estado será elaborado por el Ministerio de Economía y Hacienda conforme a las correspondientes técnicas de evaluación y al sistema de tributos y demás derechos que hayan de regir en el respectivo ejercicio.

La estructura de ingresos distingue entre centros gestores (orgánica) y naturaleza de los gastos (económica).

La clasificación económica de los ingresos, al igual que la de los gastos se estructura en capítulos, artículos y conceptos.

Cuadro. Clasificación economica del estado de ingresos

A) Operaciones corrientes

Capítulo 1. Impuestos directos.

Capítulo 2. Impuestos indirectos. 
Capítulo 3. Tasas y otros ingresos.

Capítulo 4. Transferencias corrientes.

Capítulo 5. Ingresos patrimoniales.

B) Operaciones de capital

Capítulo 6. Enajenación de inversiones reales.

Capítulo 7. Transferencias de capital.

Capítulo 8. Activos financieros.

Capítulo 9. Pasivos financieros.

\section{CONTENIDO DE LOS PRESUPUESTOS GENERALES DEL ESTADO}

Como se ha señalado en el epígrafe anterior la Constitución española en su artículo 134.2 define los Presupuestos Generales del Estado como: «La totalidad de los gastos e ingresos del sector público estatal» ampliando el concepto de la Ley General Presupuestaria de 4 de enero de 1977 que en su artículo 48 los definía como la expresión cifrada, conjunta y sistemática de las obligaciones que, como máximo pueden reconocer el Estado y sus Organismos Autónomos, y de los derechos que se prevean liquidar durante el correspondiente ejercicio. Si bien en el artículo 51 establecía que a los Presupuestos Generales del Estado se unirán el Presupuesto resumen de los organismos autónomos comerciales, industriales, financieros y otros análogos y el. Presupuesto resumen de la Seguridad Social.

En el mismo sentido del artículo 134.2 de la Constitución el nuevo Texto Refundido de la Ley General Presupuestaria de 23 de septiembre de 1988 establece en su artículo 50 que integran los Presupuestos Generales del Estado:

a) El Presupuesto del Estado y los Presupuestos de los organismos autónomos a que se refiere el artículo 4 de la presente Ley, con la pormenorización exigida por la misma, es decir, organismos autónomos de carácter administrativo y de carácter comercial, industrial, financiero o análogos.

b) El presupuesto de la Seguridad Social.

c) Los presupuestos de las sociedades estatales.

d) Los presupuestos del resto de entes del sector público estatal a que se refiere el artículo 6 de la presente Ley. 
Es decir, conforme al artículo 50 del Texto Refundido de la Ley General Presupuestaria, los Presupuestos Generales del Estado contienen los estados de ingresos y gastos del sector público estatal.

También en cuanto al contenido de los Presupuestos Generales del Estado el artículo 51 del Texto Refundido establece que contendrán:

a) Los estados de gastos en los que se incluirán con la debida especificación, los créditos necesarios para atender al cumplimiento de las obligaciones. En dichos estados se especificará la dotación al fondo de compesación interterritorial.

b) Los estados de ingresos en los que figuren las estimaciones de los distintos derechos económicos a liquidar en el ejercicio.

c) Los estados financieros de las sociedades estatales.

\section{EL CICLO PRESUPUESTARIO}

La Ley de Presupuestos, en cuanto que supone un plan de actuación, se desarrolla en las siguientes fases de repetición cíclica:

1. Formación que se descompone en:

a) Elaboración del Proyecto (Gobierno).

b) Aprobación del Proyecto (Parlamento).

2. Ejecución (Poder ejecutivo).

3. Control (Poder ejecutivo, Tribunal de Cuentas y Parlamento).

El proceso se inicia a comienzos del ejercicio anterior a su vigencia, la discusión y elaboración se produce en el último trimestre para su aprobación antes de finalizar el año.

Su ejecución se desarrolla a lo largo del correspondiente ejercicio económico.

El control lo es tanto simultáneo a la ejecución del Presupuesto como a posteriori, pudiendo ser «interno», o realizado por los propios órganos de la Administración, "externo», llevado a cabo por órganos independientes de la Administración (Tribunal de Cuentas), $y$ «político» o realizado por el propio órgano legislativo.

\section{Elaboración}

El artículo 134.1 de la Constitución atribuye al Gobierno la competencia para elaborar los Presupuestos Generales del Estado.

El proceso de elaboración del Proyecto de Ley de Presupuestos podemos dividirlo en tres fases: 
- Confección de los Anteproyectos parciales.

- Redacción del Anteproyecto y aprobación por el Gobierno.

- Remisión del Proyecto a las Cortes.

\subsection{Confección de los Anteproyectos parciales}

La regla primera del artículo 54 del TRLRL establece que los órganos constitucionales, los departamentos ministeriales y los demás órganos del Estado con dotación diferenciadas en los Presupuestos Generales del Estado remitirán al Ministerio de Economía y Hacienda, antes del primero de mayo de cada año los correspondientes anteproyectos de estados de gastos. Los Ministerios remitirán también los de los organismos autónomos a ellos adscritos.

El proceso de elaboración se inicia con la publicación en el «Boletín Oficial del Estado» de la correspondiente Orden del Ministerio de Economía y Hacienda por la que se dictan las normas para la elaboración de los Presupuestos Generales del Estado para siguiente ejercicio.

\subsection{Redaccion y aprobacion del Anteproyecto}

Corresponde al Ministerio de Economía y Hacienda la importante tarea de ajustar y armonizar las propuestas de gastos de los distintos órganos estatales y de los restantes departamentos, elaborando el Anteproyecto de Presupuestos (art. 9.5) y regla segunda del artículo 54 de la LGP.

Formado el Anteproyecto de la Ley de Presupuestos, el Ministerio de Economía y Hacienda lo eleva al Gobierno para su aprobación y transformación en Proyecto de Ley (regla tercera del art. 54 LGP). EI anteproyecto de Presupuestos de la Seguridad Social se somete a la aprobación del Gobierno conjuntamente por los Ministerios de Economía y Hacienda y de Trabajo y Seguridad Social (art. 148 LGP).

\subsection{Remision del Proyecto a las Cortes}

«El Gobierno deberá presentar ante el Congreso de los Diputados los Presupuestos Generales del Estado al menos tres meses antes de la expiración del año anterior.» (art. 134.3 CE)

El artículo 55.1 de la LGP concreta en el día 1 de octubre la fecha tope para la remisión del proyecto a las Cartas para su aprobación enmienda o devolución, disponiendo el mismo precepto que se unan al proyecto los documentos que acompañaron al anteproyecto en su evaluación al Gobierno, documentación anexa que viene enumerada en la regla tercera del artículo 54 de la LGP. 


\section{Aprobación}

Recibido el Proyecto de la Ley de Presupuestos, su tramitación es semejante a la de una ley ordinaria salvo algunas peculiaridades a las que posteriormente haremos referencia.

De conformidad con los artículos 66.2 y 134.1 de la $C E$, la aprobación de los Presupuestos es competencia privativa de las Cortes Generales, sin que, en consecuencia, pueda procederse a su aprobación por medio de Decreto Ley o Decreto legislativo, ni la delegación en las Comisiones Legislativas Permanentes (art. 75.3 CE).

En cuanto a las peculiaridades que anteriormente aludiamos, se concretan en lo dispuesto por el artículo 134.6 de la CE a tenor del cual «toda proposición o enmienda que suponga aumento de los créditos o disminución de los ingresos presupuestarios requerirá la conformidad del Gobierno para su tramitación».

La evidente dificultad que plantea la aplicación literal del citado precepto con relación a las enmiendas a la propia Ley de Presupuestos, ha sido resuelta por el Reglamento del Congreso y el Reglamento del Senado en el sentido de exigir para la admisión a trámite de las enmiendas que supongan aumento de crédito la simultánea propuesta de una baja de igual cuantía en la misma sección presupuestaria.

En el caso de que no se aprobase en proyecto de la Ley de Presupuestos antes del primer día del ejercicio económico correspondiente, se considerarán automáticamente prorrogados los presupuestos del año anterior hasta la aprobación de los nuevos (arts. 134.4 CE y 56.1 LGP).

La prórroga no afectará a los créditos para gastos correspondientes a servicios o programas que deban terminar en el ejercicio cuyos presupuestos se prorrogan (art. 56.2 LGP).

\section{Créditos extraordinarios y suplementos de crédito}

A lo largo del ejercicio económico y ante la inexactitud de las previsiones efectuadas, puede surgir la necesidad de realizar gastos para los cuales no exista crédito en el Presupuesto o resulta insuficiente el concedido. En estos casos es necesario rectificar las previsiones iniciales y abrir créditos adicionales (créditos extraordinarios o sumplementos de créditos).

De conformidad con el artículo 64.1 de la LGP los requisitos para que se conceda un crédito extraordinario o un suplemento de crédito son:

a) Que el gasto no pueda demorarse hasta el ejercicio siguiente.

b) Que no exista crédito en el Presupuesto o sea insuficiente y no ampliable el consignado. 
En cuanto al procedimiento, éste viene contemplado en el artículo 64.1 de la LGP, exigiéndose informe de la Dirección General de Presupuestos y dictamen del Consejo de Estado.

Aprobado por el Gobierno, se remite como Proyecto de Ley a las Cortes Generales, especificando el recurso que haya de financiar el mayor gasto público.

El apartado 2 del artículo 64 de la LGP establece determinadas especialidades para la concesión de créditos adicionales a los organismos autónomos, regulándose en el artículo 65 los casos en que «con carácter excepcional» puede el Gobierno conceder anticipos de Tesorería para atender gastos inaplazables, con el límite en cada ejercicio de 1 por 100 de los créditos autorizados por la Ley de Presupuestos Generales del Estado.

\section{Ejecución}

La vida legal del Presupuesto comienza con la ejecución de los gastos contenidos en el mismo para la satisfacción de las necesidades públicas. Pero la realización del gasto requiere la previa existencia de crédito presupuestario. El artículo 48 de la LGP establece que «los Presupuestos Generales del Estado constituyen la expresión cifrada, conjunta y sistemática de las obligaciones que como máximo puede reconocer el Estado y sus organismos autónomos...», señalando su artículo 60 que serán nulos de pleno derecho las obligaciones que infrinjan este límite.

El gasto público se realiza por medio de una serie de actos jurídicamente entrelazados que forman un auténtico procedimiento administrativo. Nos vamos a referir únicamente a las diversas fases que constituyen el procedimiento ordinario, sin entrar en las especialidades que presentan determinados expedientes de gastos.

La LGP se refiere a las distintas fases en la gestión de los gastos disponiendo en su artículo 74: «corresponde a los órganos constitucionales, a los Jefes de departamentos ministeriales y a los demás órganos del Estado con dotaciones diferenciadas en los Presupuestos Generales del Estado aprobar los gastos propios de los servicios a su cargo, salvo los casos reservados por la Ley a la competencia del Gobierno, así como autorizar su compromiso y liquidación, e interesar del Ministerio de Economía y Hacienda la ordenación de los correspondientes pagos", estableciendo a continuación que la referida competencia en los organismos autónomos viene atribuida a sus directores o presidentes, tanto la disposición de los gastos como la ordenación de los pagos, sin perjuicio de las competencias que las leyes otorgan al Gobierno. 
Las referidas competencias son delegables en los términos que establezcan las disposiciones reglamentarias.

En base a lo expuesto, en la serie de operaciones que comporta el gasto público podemos distinguir dos fases claramente diferenciadas:

- La ordenación del gasto.

- La ordenación del pago.

La primera conduce a la asunción por el Estado de una obligación. La segunda fase se encamina al cumplimiento por el Tesoro público de dicha obligación.

Desde el punto de vista orgánico la ordenación del gasto se lleva a cabo en los centros gestores, mientras que la ordenación del pago se realiza por el Ministerio de Economía y Hacienda.

Siguiendo a la Orden del Ministerio de Economía y Hacienda de 31 de marzo de 1986 sobre la contabilidad de los centros gestores del presupuesto hemos de diferenciar:

1. Autorización.

2. Disposición o compromiso.

3. Reconomiento de la obligación.

4. Ordenación del pago.

5. Pago.

\section{Autorización para realizar el gasto}

La orden del Ministerio de Economía y Hacienda de 31 de marzo de 1986 define esta fase como el «acto en virtud del cual el Ministro o autoridad competente acuerda la realización de un gasto, calculado en forma cierta o aproximada reservando, a tal fin, la totalidad o una parte del crédito presupuestado".

La propuesta de gastos debe de contener determinados datos:

- Aplicación presupuestaria.

- Importe del gasto.

- Destino o finalidad.

- Período de tiempo a que se refiere.

- Forma de efectuar el pago.

- Certificado de existencia de crédito.

Toda propuesta de gasto ha de ser remitida a la Intervención Delegada para su fiscalización previa. 


\section{Compromiso de gasto}

Se diferencia de la fase anterior en que ésta tiene ya carácter externo vinculando a la Administración.

La Orden del Ministerio de Economía y Hacienda anteriormente citada, establece que «el importe por el que se acuerda el acto y, por tanto el de la operación contable del compromiso ha de estar, en todo caso, exactamente determinado, al igual que las condiciones de realización de la obra, prestación del servicio, etc.».

\section{Obligación de pago}

Realizada por el acreedor la prestación acordada en favor de la Administración, surge para ésta la obligación de pagar una vez acreditado y justificada la contraprestación (certificación de obra, factura de suministro, etc.) (arts. 43 y 78 LGP).

\section{Ordenación del pago}

Consiste en la emisión por la autoridad competente de una Orden a la Tesorería del Estado para que ésta satisfaga una obligación (arts. 75 y ss. LGP).

La ordenación del pago se efectúa a través del correspondiente mandamiento o libramiento, que puede ser «en firme» o «a justificar».

\section{Pago}

Junto a la fase anterior, existe el pago material consistente en la salida de fondos de la Tesorería del Estado para hacer frente a las órdenes emanadas del ordenador de pagos.

La Ley General Presupuestaria en su artículo 117 entre las funciones encomendadas al Tesoro Público señala las de «recaudar los derechos y pagar las obligaciones del Estado».

\section{Liquidación y cierre del ejercicio}

El sistema de cierre del ejercicio presupuestario establecido por la Ley $11 / 1977$, de 4 de enero, General Presupuestaria, resultó profundamente modificado por obra de la Ley 44/83, de 28 de diciembre, de presupuestos para 1984 que suprimió los períodos de ampliación de cuatro meses y complementario de un mes previsto con anterioridad, lo que supuso la derogación mediante una Ley 
anual de presupuestos de preceptos de la anterior Ley General Presupuestaria que sufría, una vez más, un proceso de vaciamiento, con la consiguiente pérdida de valor como Ley General o codificadora.

El Texto Refundido de la LGP aprobado por Decreto Legislativo $1091 / 88$, de 23 de septiembre, recoge la modificación realizada por la Ley $44 / 83$, de 28 de diciembre, y establece en su artículo 83 que «el Presupuesto de cada ejercicio se liquidará en cuanto a la recaudación de derechos y al pago de obligaciones el 31 de diciembre del año natural correspondiente reiterando en su apartado tercero una regla ya contenida en el artículo 81 de la derogada Ley General Presupuestaria, al establecer que «todos los derechos pendientes de cobro y las obligaciones pendientes de pago a la liquidación del Presupuesto quedarán a cargo del Tesoro público según sus respectivas contracciones».

\section{CONCEPTOS Y EFECTOS DE LOS PRESUPUESTOS DE LAS ENTIDADES LOCALES}

La Ley Reguladora de las Bases del Régimen Local, 7/85 de 2 de abril (LBRL) define el presupuesto de las entidades locales en términos análogos a los del artículo 48 del RDL 1091/88 de 23 de septiembre, por el que se aprueba el Texto Refundido de la Ley General Presupuestaria (TRLGP), es decir, «como la expresión cifrada, conjunta y sistemática de las obligaciones que, como máximo, pueden reconocer $y$ de los derechos cuyo vencimiento o que se prevean realizar durante el correspondiente ejercicio económico.

Como se deduce de la definición anterior, los efectos son los mismos que los del Presupuesto del Estado, así respecto de los ingresos constituye únicamente una mera previsión, mientras que se subraya el carácter limitativo respecto de los gastos. De esta forma el artículo 448 del Real Decreto Legislativo 781/86 de 18 de abril (RDLRL) consagra el principio de especialidad cualitativa y cuantitativa, reproduciendo al fin, de una manera sintética lo preceptuado en los artículos 59 y 60 de TRLGP.

El carácter limitativo de los créditos es reiterado en el artículo 7 del Real Decreto 2513/82 (Reglamento no derogado expresamente por el RDLRL $y$, por tanto, vigente en lo que no se oponga a aquél o a la LBRL), el cual establece, no obstante, la condición de ampliables de aquéllos cuya cuantía venga determinada en función del ingreso obtenido por un concepto obtenido directamente vinculado a aquéllos.

Por último, el artículo 449 del RDLBRL permite los gastos plurianuales subordinados «al crédito que para cada ejercicio autorice 
el respectivo presupuesto»; en términos semejantes, por tanto, a lo que expresa el artículo 61 en el ámbito de la Administración del Estado el TRLGT.

\section{LOS PRINCIPIOS PRESUPUESTARIOS EN LA ESFERA LOCAL}

\section{a) Autonomía}

Como manifestación en el ámbito financiero de la que se reconoce a las Corporaciones locales por la Constitución española en sus artículos 137 y siguientes.

\section{b) Unidad}

Este principio, nuevo en la Administración local desde la entrada en vigor de la Ley 7/85 de 2 de abril, rompe con la habitual distinción entre Presupuestos ordinarios y extraordinarios; para observar con mayor claridad el proceso evolutivo de este principio.

La delimitación entre Presupuestos ordinarios y extraordinarios aparece ya en las Leyes municipales de 20 de agosto de 1870 (artículos 126 y 135) y de 20 de octubre de 1877 (artículos 133 y 142).

Sin embargo, la doctrina recogiendo la práctica administrativa derivada de muy diversas disposiciones distinguía:

- Por razón de su naturaleza «los Presupuestos ordinarios, extraordinarios y los adicionales».

- Teniendo en cuenta su extensión «los generales de los particulares".

Los Presupuestos ordinarios se llaman así, se decía entonces, «porque se han de formar periódicamente todos los años, comprendiendo los recursos y gastos de carácter permanente, aunque fuera variable su cuantía», y los extraordinarios "son aquellos que se forman únicamente para cubrir atenciones imprevistas, para satisfacer alguna deuda o para cualquier otro objeto de importancia no determinada en el Presupuesto ordinario o resultaren insuficientes los recursos que en éste se consignaren».

Los Presupuestos adicionales, por su parte, tienen su origen en la Real Orden de 15 de junio de 1850 que dispuso cerrar las cuentas en el mes de diciembre y formar estos presupuestos en el mes de enero a fin de recoger las resultas, una vez terminado el período de ampliación.

Los Presupuestos particulares son los que se refieren a algún servicio especial del cual reciben la denominación (carcelarios los formados para subvenir a las necesidades de las cárceles de 
beneficiencịa si están llamados a contener obligaciones y recursos de los establecimientos del ramo, etc.).

La doctrina de la época recordaba, sin embargo, el principio de unidad presupuestaria, conectándole tanto con el principio de universalidad como con el de unidad de caja.

La diferenciación entre Presupuestos ordinarios y extraordinarios, fue objeto de especial atención en los Proyectos sobre régimen local, en concreto, el de Alfonso González de octubre de 1901 y el de Manuel Burgos Mazo de 14 de noviembre de 1919. Es, no obstante, en el Estatuto municipal de 8 de marzo de 1924 (arts. 292, 293, 298 y 299) cuando se establece una verdadera línea divisoria entre Presupuestos ordinarios y extraordinarios, prohibiéndose severamente el déficit inicial en los primeros. Los extraordinarios salvo el caso de calamidades públicas, sólo pueden contener gastos de primer establecimiento relativos a los servicios municipales, con absoluta exclusión de todo gasto ordinario de entretenimiento o conservación de los mismos servicios.

La Ley de Bases de Régimen Local de 17 de julio de 1945 confirmó esta división regulándose conjuntamente, incorporando a la vez los presupuestos especiales (art. 249).

Esta clasificación en tres tipos de presupuestos (ordinarios, extraordinarios y especiales) se confirma en las siguientes o mejor posteriores Leyes de Régimen Local: texto articulado de 16 de diciembre de 1950 (arts. 648 y ss.) y texto articulado y refundido de 24 de junio de 1955 en sus artículos 675 y siguientes.

El Real Decreto Legislativo $11 / 79$, de 20 de julio, operando sobre la clasificación anterior, avanzó en el principio de unidad presupuestaria, disponiendo en su artículo 11 que las Corporaciones locales «elaborarán y aprobarán anualmente un Presupuesto General consolidado en el que se integren: el Presupuesto ordinario, los Presupuestos especiales de urbanismo y de los servicios, órganos y demás entes dependientes de la Corporación al que se unirán como anexos los Presupuestos extraordinarios.

Este precepto legal (dictado apenas transcurridos poco más de dos años desde la promulgación de la, hasta hace muy poco vigentes, LGP. permitió un efectivo e inteligente avance en el aspecto material y formal del principio de unidad presupuestaria local, ya que unificaba en un solo acto corporativo todos los presupuestos ordinarios y especiales, de los presupuestos extraordinarios, de las sociedades mercantiles, haciendo concurrir en el acto de aprobación del presupuesto general todos los elementos significativos de la gestión económica local de ejercicio correspondiente, que podía, así, ser objeto de una visión y ordenación unitaria por la Corporación local (no 
olvidemos que hasta entonces presupuestos extraordinarios y especiales se elaboraban y regían, en el aspecto temporal, de forma no coordinada con los anteriores).

El Real Decreto Legislativo 3/81, de 16 de enero, y la Ley $40 / 81$, de 28 de octubre, suprimen la tipología tradicional creando una nueva de "presupuesto ordinario y presupuesto de inversiones".

Llegamos por fin a la Ley 7/85 que dispone en su artículo 111.1 . «Las entidades locales aprueban anualmente un presupuesto único integrado por el de la propia entidad y los de todos los organismos y empresas locales con personalidad jurídica propia dependientes de aquélla». En parecidos términos, aunque más exhaustivamente, el artículo 443 del TRLRL del Real Decreto Legislativo 781/86, de 18 de abril expresa claramente el principio de unidad, del que se pueden extraer dos características principales:

- Seguir las pautas y técnicas de los Presupuestos Generales del Estado.

- Por alejarse, completamente, de las normas anteriores que admitían una pluralidad formal, material y estructural de presupuestos, tanto en su fase de mayor diversidad (tipología trimembre de presupuestos ordinarios, extraordinarios y especiales), como la atenuada de tipología bimembre (presupuestos ordinarios y presupuestos de inversión).

\section{c) Universalidad}

Se halla consagrada en el artículo 448.2 de TRLBL que reproducen en lo fundamental lo dispuesto en el artículo 59.2 del TRLGT.

\section{d) No afectación}

Principio no formulado de manera expresa en el ámbito local, aunque parece evidente su total aplicación en las Haciendas locales en cuanto presupuesto indispensable de cualquier economía financiera, aunque se admitan excepciones al mismo como observábamos al comienzo de este apartado.

\section{e) Equilibrio}

Este principio, superado en los Presupuestos del Estado se imponen, por el contrario a los entes locales como un deber jurídico, por el temor de aquél a los desarreglos financieros de estos entes que, en última instancia, irán a recaer sobre el propiọ Estado. La Ley 7/85 se refiere tan sólo a la nivelación presupuestaria como posible causa de impugnación del Presupuesto. EI TRLRL sí recoge expresa- 
mente el principio de nivelación al exigir que «el Presupuesto deberá aprobarse sin déficit inicial» (art. 444.4). Acompaña a este mandato otro recogido en el mismo artículo, referido a los ingresos y gastos de carácter ordinario al preceptuarse que «el Presupuesto no podrá contener créditos destinados a obligaciones de carácter ordinario que exceden al importe de sus ingresos asimismo ordinarios".

La nivelación presupuestaria, en los dos aspectos antes citados, es decir, la presupuestaria general y la de ingresos y gastos ordinarios, son exigibles en la liquidación de los presupuestos, debiéndose adoptar las medidas oportunas para corregir el déficit (art. 452 TRLRL).

\section{f) Anualidad en la aprobación}

El artículo 112.1 LBRL establece la periodicidad anual del presupuesto local. De acuerdo con este precepto el ejercicio presupuestario coincide con el año natural, con evidente paralelismo a lo dispuesto en el artículo 49 del TRLGP.

\section{g) Unidad de caja}

El principio de unidad de caja no puede ser concebido en términos más restringidos que en el régimen local. El artículo 441.1 del TRLRL determina que «constituyen la tesorería de las respectivas entidades locales... todos los fondos, valores y efectos..., tanto por operaciones presupuestarias como extrapresupuestarias" y que "se ingresará y custodiará en la caja de la corporación, de la cual serán claveros el ordenador de pagos, el interventor y el tesorero (442.1) quedando prohibida la existencia de cajas especiales (442.2)».

\section{REFERENCIA AL PROYECTO DE LEY REGULADORA DE LAS HACIENDAS LOCALES}

Texto inserto en el «BOC» núm. 85.1, de 8 de junio de 1988, hoy Ley 39/1988, de 28 de diciembre («Boletín Oficial del Estado» del 30 de diciembre de 1988, núm. 313)

De una manera sintética puede señalarse:

1. - El principio de unidad se articula mendiante: a) un Presupuesto general en el que se integran el de la propia entidad, sus organismos autónomos y los estados de previsión de las sociedades mercantiles (art. 146.1); b) un estado de consolidación (art. 148.1.c), y c) un acuerdo de aprobación que será único (art. 150.5). 
2.- El principio de universalidad, se anuncia, pero sin especial énfasis ni precisión (art. 147), a la vez que se restringe o circunscribe al ámbito de actuación de cada personificación, admitiéndose fuertes excepciones, como la generación de créditos a que se refiere el artículo 163, excepción ésta que, de no ser interpretada en sentido estricto, puede suponer un grave portillo contra el principio de unidad, permitiendo que bajo esta singular forma de modificación de créditos se aprueben, real y verdaderamente, nuevos Presupuestos, que se agregarían al aprobado originariamente como aparentes Presupuestos únicos.

3. - El principio de no afectación de ingresos a gastos se recoge con carácter expreso, artículo 147.2, si bien se tienen en cuenta de una forma amplia en los créditos ampliables, en la incorporación de créditos y en la cuantificación del remanente de tesorería.

4. - El principio de presupuesto bruto, es recogido expresamente en el artículo 147.3, aunque se fijan excepciones en los casos en que la Ley lo autorice de modo expreso, en los supuestos de devoluciones de ingresos que se declaren indebidos por los Tribunales $u$ otras autoridades competentes.

5. - La unidad de caja se enuncia como función encomendada a la tesorería, abarcando los recursos financieros de la entidad local y de sus organismos autónomos (arts. 176.1 y 2 y 178.b).

6. - Por último, el principio de nivelación no se expresa en su sentido estricto de equilibrio financiero, conceptuándose negativamente, y omitiéndose totalmente cualquier referencia a la nivelación o cobertura de los gastos corrientes por los ingresos corrientes (cobertura que habría de alcanzar, asimismo, las cuotas de amortización de préstamos y empréstitos).

\section{ESTRUCTURA DE LOS PRESUPUESTOS LOCALES}

El Presupuesto consta de dos partes (arts. 444.2 y 3 del TRRLR): estado de gastos e ingresos y bases de ejecución. En relación con los primeros es de destacar el deber jurídico que tiene la Corporación de incluir en el Presupuesto los créditos necesarios para hacer frente a los gastos obligatorios. Su omisión permitiría interponer recursos contra los presupuestos. Las bases de ejecución equivalen al articulado de la Ley de Prespuestos, pues en llas se contienen las disposiciones pertinentes a la ejecución del Presupuesto; lógicamente el límite se encuentra en aquellos preceptos o disposiciones que requieran legalmente procedimiento y/o solemnidades distintas del Presupuesto. 
Por lo que a la estructura propiamente dicha, es decir, la ordenación de ingresos y gastos, el artículo 53.3 del TRLGT, en términos sensiblemente equivalentes a sus precedentes (art. 53.2 LGP), dispone que «los Presupuestos de las entidades locales se adaptarán a la estructura que con carácter general se establezca para el sector público por el Ministerio de Economía y Hacienda, sin perjuicio de las peculiaridades de aquéllas». La LRBRL, por su parte, señala en el artículo 112.2 que «la Administración del Estado determinará con carácter general la estructura de los presupuestos de las entidades locales", igualmente el artículo 444.1 del TRLRL. En cuanto al régimen jurídico concreto, éste viene regulado por la Orden de 14 de noviembre de 1979, por la que se aprueba la estructura a que deberán adaptarse los presupuestos de las Corporaciones locales. En ella se establece para los gastos una triple clasificación, económica, funcional y orgánica, cuyos desarrollos se contienen en anexos a la citada disposición.

\section{ELABORACION Y APROBACION DE LOS PRESUPUESTOS LOCALES}

Dispone el artículo 445 del TRRLR que el proyecto se formará por el Presidente de la Corporación y lo elevará al Pleno, con tiempo suficiente para que entre en vigor con el comienzo del ejercicio, acompañado de una Memoria explicativa y demás documentos enumerados exhaustivamente en dicho precepto.

Corresponde al Pleno de la Corporación (art. 22.2.e LBRL) la aprobación del texto presupuestario. La Ley de Bases, modifica un criterio fundamental al no incluir este acuerdo entre aquellos que requieren una mayoría cualificada para ser aprobados, siendo suficiente, por tanto, la mayoría simple de los miembros presentes en la sesión.

El Presupuesto inicialmente aprobado, será expuesto al público por un período de quince días para oír las alegaciones y reclamaciones que contra el mismo se presente. Tales reclamaciones serán resueltas mediante acuerdo expreso que apruebe definitivamente los Presupuestos. De no haber reclamaciones, transcurrido el período de información, se entenderá el Presupuesto definitivamente aprobado sin necesidad de adoptar segundo acuerdo.

Dispone el artículo 112.3 de la LBRL que una vez aprobados definitivamente cada uno de los Presupuestos integrantes del general de la Corporación y el consolidado se insertarán resumidos por capítulos en el tablón de anuncios y en el Boletín Oficial de la Provincia. En el plazo de treinta días deberá remitirse copia de los 
mismos a la Administración del Estado y a la Comunidad Autónoma correspondiente (art. 453.1 TRLRL).

\section{Recursos contra el Presupuesto}

La Ley de Bases suprime el recurso económico-administrativo en virtud de la consideración de que tal instancia ante un órgano dependiente de la Administración del Estado iría en detrimento de la autonomía local. De esta forma el sistema de respuesta contra el Presupuesto local pivota alrededor del recurso de reposición potestativo o el acceso directo a la jurisdicción contencioso-administrativa.

Señala el artículo 447.1 del TRLRL los sujetos legitimados para entablar recursos contra los presupuestos, precepto que habrá que poner en relación con los señalados en el artículo 63.1 LRRL, esto es, la Administración del Estado y la de las Comunidades Autónomas para cerrar el sistema.

Por último, el artículo 447.2 del TRLRL señala los motivos en los que se puede sustentar el recurso.

\section{Entrada en vigor y prórroga}

El Presupuesto, a tenor de lo dispuesto en el artículo $446.4 \mathrm{del}$ TRLRL, entrará en vigor, en el ejercicio correspondiente, una vez publicado y transcurrido el plazo previsto en el artículo 70.2 de la Ley 7/85. Este precepto remite a su vez al artículo $112.3 \mathrm{del}$ mismo cuerpo legal en el que se establece el deber de publicación de los Presupuestos. Al igual que el Presupuesto del Estado, si el de las Corporaciones locales no hubiera entrado en vigor al iniciarse el ejercicio económico, se considerarán automáticamente prorrogados los créditos iniciales del Presupuesto del ejercicio anterior, con la misma salvedad (téngase en cuenta lo dispuesto en el art. 56.2 del TRLGP) de que la prórroga no afectará a los créditos para servicios o programas que deban concluir en el ejercicio anterior o que se financiaron con ingresos extraordinarios.

\section{EJECUCION DE LOS PRESUPUESTOS LOCALES}

1. Disposición de gastos. Corresponde al Presidente de la entidad cuando se trate de los de carácter ordinario y de los demás precisos para la contratación de obras, servicios y suministros con los límites a que se refiere el artículo 21.1 LBRL. Corresponde al Pleno la de los gastos que rebasen los anteriores límites o cuando la Ley le atribuya expresamente la competencia. Conviene tener en cuenta, no 
obstante, la ampliación competencial del alcalde derivada del tenor del artículo 24.c del TRLRL.

2.ㄴ La liquidación de obligaciones derivadas de los compromisos legalmente contraídos corresponde al Presidente de la Corporación, y al Pleno el reconocimiento de obligaciones correspondientes a hechos o actos producidos en ejercicios cerrados.

3. La ordenación de pagos corresponde al Presidente de la Corporación el cual debe atenerse en ella a las prioridades derivadas de la naturaleza preferente, obligatoria o voluntaria del gasto (art. 437 TRLRL).

4. - Anualidad de la ejecución. El efecto fundamental de este principio supone la anulación de los créditos no comprometidos durante la vigencia del presupuesto (art. 451 TRLRL). Se exceptúan, no obstante, los remanentes de créditos para inversiones que podrán incorporarse al presupuesto del ejercicio siguiente.

5. - Liquidación del Presupuesto. Es la operación inmediatamente posterior al cierre del ejercicio, consistente en determinar el saldo de las distintas partidas presupuestarias. De esta forma constituyen las resultas de gastos las obligaciones reconocidas y liquidadas no satisfechas el último día del ejercicio anterior, y las de ingresos los créditos pendientes de cobro y la existencia en caja a 31 de diciembre anterior (art. 451.3 TRLRL). Lógicamente, las resultas de cada presupuesto se incorporan al siguiente dando lugar al llamado presupuesto refundido, conforme determina el artículo 451.3 TRLRL. La liquidación se lleva a cabo por el Interventor y se aprueba por el Presidente de la entidad (art. 451.4 TRLRL). La liquidación se remite copia a la Administración del Estado (al Delegado de Hacienda tal y como ordena el Real Decreto 186/81, de 5 de febrero), y a la Comunidad Autónoma correspondiente dentro de los treinta días siguientes a la aprobación.

\section{DINAMICA DEL GASTO: GESTION Y CONTABILIDAD EN LA ADMINISTRACION LOCAL}

Tratando la ordenación del gasto sobre la ejecución del Presupuesto de las entidades locales deben hacerse unas reflexiones sobre un requisito necesario: la configuración presupuestaria.

Estas precisiones no son fundamentalmente de la que rigen la Hacienda pública. Sin embargo, en las Haciendas locales conviene recordar los siguientes asuntos diferenciales: 
- El Presupuesto de las entidades locales es un acto administrativo (art. 112 de la Ley $7 / 85$ y arts. 443 a 447 del Texto Refundido de Ley de Régimen Local), sometido a informe preceptivo de intervención artículo 445.h.

- El principio de competencia respecto a la aprobación y modificación de los Presupuestos que fijado como atribución propia no delegable del Pleno, artículos 22.2.1 y 23.2.b de la Ley $7 / 85$.

La existencia de crédito presupuestario previo y adecuado, es requisito preliminar de la dinámica de la ordenación del gasto y se acredita, en general, por certificación contable de la intervención, sin perjuicio de su constancia, además, en otros significativos.

Así la anterior reserva de crédito presupuestario que tenía un carácter provisional se convierte en definitiva. En consecuencia, la disposición o compromiso del gasto produce la afección del crédito presupuestario a la finalidad concreta comprometida.

En la contratación administrativa la adjudicación definitiva perfecciona el contrato produciendo el nacimiento de un vínculo obligatorio entre la Administración y el contratista.

\section{Reconocimiento de la obligación}

Esta fase en el Decreto 6/62 de 18 de enero sobre mecanización de la contabilidad de gastos públicos, y Orden del Ministerio de Hacienda de 22 de enero de 1962 se menciona como obligación y obligaciones contraídas. Esta fase concreta y registra el crédito frente a la entidad local que como tal crédito presupuestario quedará completamente agotado.

La obligación de pago es un concepto exigido por el procedimiento presupuestario según señala el artículo 182.3 del Texto Refundido, por el que sólo serán exigibles a las entidades locales las obligaciones de pago que resulten de la ejecución de sus respectivos presupuestos o los derivados de sentencia judicial firme.

El principio de anualidad marca o determina el presupuesto a que ha de referirse la obligación de pago. El artículo 448.3 sólo permite contraer obligaciones en el año natural que se realicen del propio ejercicio presupuestario.

Además, el procedimiento presupuestario impide que puedan autorizarse o adquirirse compromisos de gasto momentos de la 
dinámica del gasto, como sucede en la detallada regulación de la contratación administrativa.

Autorización del gasto, es un acto interno de la Administración que produce ostensiblemente una reserva de crédito presupuestario para una atención o finalidad concreta, que puede, por consiguiente, ser dejado sin efecto en cualquier momento sin transcendencia alguna respecto a terceros ya que no refleja vínculo alguno de tipo obligacional.

Representa la primera fase, gestora y contable en la Administración del Estado y a nuestro criterio puede ser utilizado por las entidades locales cuya complejidad de gestión así lo demande no obstante haberse omitido su referencia a los textos legales que rigen el mundo local.

En general se inicia el expediente de gasto con una propuesta de gasto según señala el artículo 435 del Texto Refundido, del órgano competente que ha de contener los requisitos propios de la regulación de la materia administrativa de que se trate, y la fiscalización de la intervención según señalan artículos 435, 454 y 455 del Texto Refundido y el artículo 4.1 del Real Decreto 1174/87.

La fase de autorización no aparece regulada en la Ley de Bases ni en el Texto Refundido si bien procede su aplicación por la regla de la subsidiariedad prevista en el artículo 5 .e de la Ley $7 / 85$.

\section{Disposición o compromiso de gasto}

Esta fase es fundamental en la ordenación del gasto y es relevante para con terceros por establecer una relación jurídica en la cual la Administración aparece como potencialmente obligada.

Así la anterior reserva de crédito presupuestario que tenía un carácter provisional se convierte en definitiva. En consecuencia la disposición o compromiso del gasto produce la afección del crédito presupuestario a la finalidad concreta comprometida.

En la contratación administrativa la adjudicación definitiva perfecciona el contrato produciendo el nacimiento de un vínculo obligatorio entre la Administración y el contratista.

\section{Reconocimiento de la obligación}

Esta fase en el Decreto 6/62 de 18 de enero sobre mecanización de la contabilidad de gastos públicos, y Orden del Ministerio de Hacienda de 22 de enero de 1962 se menciona como obligación y obligaciones contraídas. Esta fase concreta y registra el crédito frente a la entidad local que como tal crédito presupuestario quedará completamente agotado. 
La obligación de pago es un concepto exigido por el procedimiento presupuestario según señala el artículo 182.3 del Texto Refundido, por el que sólo serán exigibles a las entidades locales las obligaciones de pago que resulten de la ejecución de sus respectivos Presupuestos o los derivados de sentencia judicial firme.

El principio de anualidad marca o determina el Presupuesto a que ha de referirse la obligación de pago. El artículo 448.3 sólo permite contraer obligaciones en el año natural que se realicen del propio ejercicio presupuestario.

Además, el procedimiento presupuestario impide que puedan autorizarse $o$ adquirirse compromisos de gastos y obligaciones por cuantía superior a los créditos aprobados, que tendrán carácter limitativo según especifica el artículo 448 del Texto Refundido, sancionándose con nulidad de pleno derecho los acuerdos, resoluciones y actos administrativos en general que se adopten careciendo de crédito presupuestario suficiente para la finalidad específica de que se trate según establece el artículo 435.2 del Texto Refundido.

La nulidad que establece el artículo antes mencionado afecta a la validez de las obligaciones de las entidades locales, pero solamente por lo que se refiere a las que no son de carácter legal como las derivadas de la contratación administrativa $u$ otorgamiento de funciones.

La exigibilidad a que se refiere el artículo 182.3 del Texto Refundido no es la propia de las obligaciones, sino la exigibilidad de pago que queda enervada de no poderse canalizar presupuestariamente por falta de crédito presupuestario.

Como indica la doctrina esta nulidad de las obligaciones públicas por falta de crédito resulta desvirtuada en la práctica, bien porque en caso de que el particular haya cumplido su prestación para con el Estado su crédito nulo frente a esto que convierte en una obligación extracontractual del mismo contenido, por la indemnización de los daños y perjuicios que se le hayan causado bien por la práctica habitual de incluir en las leyes de concesión de créditos extraordinarios y suplementos de crédito una claúsula de convalidación de las obligaciones afectadas de ese vicio, extremos y condiciones que pueden trasladarse íntegramente al ámbito de las Haciendas locales.

\section{LA FISCALIZACION DEL GASTO}

Según lo establecido en el artículo 92 de la Ley de Bases de Régimen Local las funciones de control y fiscalización interna de la gestión económico financiera y presupuestaria son funciones públicas 
necesarias en todas las Corporaciones locales, aparecen especificadas legal y reglamentariamente y se confieren a los Interventores y Secretarios en plazas de tercera clase.

La función de fiscalización del gasto se manifiesta por el «informe fiscal», «informe de fiscalización» o «acto de intervención» y en su caso por los «reparos», cuya naturaleza se manifiesta por los siguientes caracteres:

- Afecta a todos los actos de gestión económico financiera y presupuestaria.

- Es un acto necesario en el procedimiento de gasto, que se diferencia del resto de los informes del Secretario e Interventor que tendrán el carácter de facultativos (art. 54 del TR).

- Constituye una faceta de control interno de las entidades locales.

- Ha de realizarse en todas las fases del gasto.

Ha de adoptar forma estricta, que puede ser concisa.

La fiscalización tiene formas y denominaciones diferentes según la correspondiente fase de ordenación del gasto o de ordenación del pago:

1. Fiscalización previa (art. 454.3.a del TR) consiste en la facultad de la intervención para examinar, antes de que se dicte el correspondiente acuerdo, todo expediente o documento en que se formulen una propuesta de gasto con objeto de conocer si su contenido y tramitación se han ajustado a las disposiciones legales que en cada caso se aplican.

Es un control de legalidad.

2. Intervención de la inversión de cantidades destinadas a realizar servicios, obras, adquisiciones y su recepción (art. 454.3.d del TR).

Respecto de la comprobación de inversiones, son aplicables subsidiariamente a las entidades locales las normas del Estado que determinan su obligatoriedad cuando excedan de tres millones de pesetas y la presencia del representante de la Intervención en la recepción provisional de las obras cuya cuantía exceda de 50 millones de pesetas (art. 54.1 de la-Ley de Contratos del Estado).

En el caso de no ser necesaria la comprobación material quedará sustituida por una certificación expedida por el jefe del centro, dependencia u organismo que expresará haberse hecha cargo del material o haberse ejecutado la obra o servicio en las condiciones establecidas. 
La función de Intervención de las inversiones guarda relación con la fase anteriormente expuesta de reconocimiento de la obligación, que en la terminología de las Corporaciones locales se utiliza más frecuentemente como obligaciones reconocidas y liquidadas (arts. 477 y 478 del TR).

3. Intervención formal de la ordenación del pago, denominada por el Texto Refundido como intervención formal del pago (artículo 454.3.c del TR).

La intervención formal de la ordenación del pago debe comprobar el debido cumplimiento de la fiscalización previa y de la intervención de la inversión, que deben preceder en todos los mandamientos de pago librados en firme.

4. La intervención material del pago, comprende el Decreto de expedición de los mandamientos de pago y las correspondientes operaciones de asiento de los mandamientos de pago y su pase a Depositaría.

Esta verificación puede seguir procedimientos propios en cada entidad local y su función es supervisar la documentación que se traslada a Caja.

\section{TECNICAS DE FISCALIZACION}

La fiscalización o intervención de los gastos, por su ámbito general requiere que se aplique o afecte a todos y cada uno de los actos de gestión en las diferentes fases del gasto, lo que ha sido objeto de críticos en cuanto puede suponer de freno o estorbo en la necesaria agilidad del trámite administrativo, toda vez, que, además, su realización había de incidir sobre las propuestas de resolución o acuerdo; al ser un control previo que podíamos denominar fiscalización plena.

Estos inconvenientes que no se deben admitir total y absolutamente en los términos que se han expresado muchas veces, han llevado a la admisión de «técnicas de muestreo» cuya autorización corresponde al Pleno de la Corporación (art. $\mathbf{4 5 5 . 3}$ del TR).

Estas técnicas fueron introducidas en la Administración del Estado en las Leyes de Presupuestos para 1983 y 1984, en aplicación de tales disposiciones la Intervención General del Estado dictó unas normas provisionales sobre muestreo, como apéndice de la Circular $7 / 83$ de 30 de junio, sobre normas, objetivos y procedimientos de auditoría.

Estas normas y técnicas se han ido adoptando por ciertas Corporaciones locales, en aplicación del artículo 5 de la LBRL, por razones de necesidad y conveniencia y ante el silencio que se guarda 
en cualquier instrucción o circular que específicamente hubiera podido dictarse para las entidades locales por Dirección General de Coordinación con las Haciendas Territoriales del Ministerio de Economía y Hacienda.

Recientemente, de acuerdo con la nueva redacción dada al artículo 95 del TRLGT ha quedado acuñado el nuevo término de «fiscalización limitada»; que se caracteriza principalmente por:

- Referirse a los ảctos de gestión de los órganos desconcentrados.

- Limitar la fiscalización a los siguientes aspectos: existencia de adecuación del crédito presupuestario; competencia del órgano; los extremos trascendentales en la gestión.

- Sujetar, posteriormente, los actos así fiscalizados a una fiscalización plena con técnicas de muestreo o de auditoría, de cuyo resultado se informará por la intervención.

Estas formas de llevar a término la función de fiscalización previa (muestreo), fiscalización limitada, además de su efecto concreto y directo en los órganos de gestión, tendrían que ser tenidas en cuenta en los informes de fiscalización del Tribunal de Cuentas, para evitar que sus resultados críticos no queden virtualmente como letra muerta abriendo un amplio portón a la gestión ilegal o irresponsable. 
REALA-1989, núm. 241. FAYOS APESTEGUIA, JOSE LUIS. DERECHO PRESUPUESTARIO ESPAÑO...

REALA-1989, núm. 241. FAYOS APESTEGUIA, JOSE LUIS. DERECHO PRESUPUESTARIO ESPAÑO... 
REALA-1989, núm. 241. FAYOS APESTEGUIA, JOSE LUIS. DERECHO PRESUPUESTARIO ESPAÑO...

REALA-1989, núm. 241. FAYOS APESTEGUIA, JOSE LUIS. DERECHO PRESUPUESTARIO ESPAÑO... 